\title{
Rede social e promoção da saúde dos "descartáveis urbanos""
}

\author{
SOCIAL NETWORK AND HEALTH PROMOTION OF HOMELESS POPULATION
}

RED SOCIAL Y PROMOCIÓN DE LA SALUD DE LOS “DESECHABLES URBANOS”

\section{Eduardo Sodré de Souza', Sandra Regina Vilchez da Silva ${ }^{2}$, Ana Maria Caricari ${ }^{3}$}

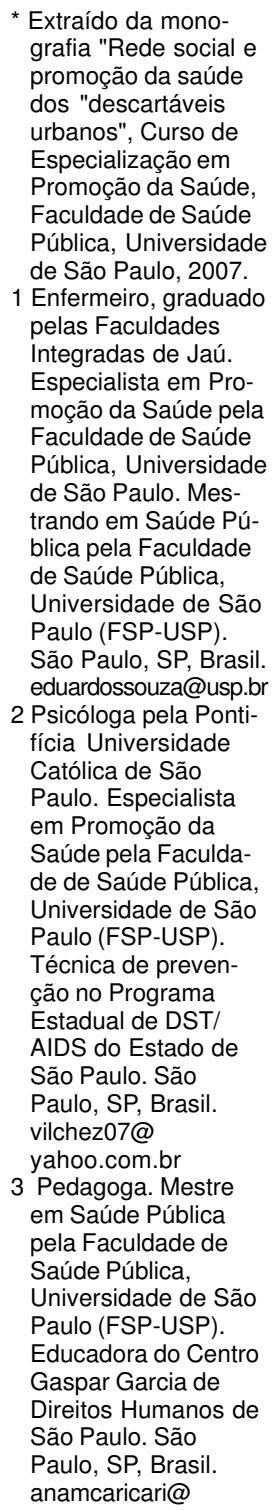

\begin{abstract}
RESUMO
Com a aceleração da globalização, uma parcela da população ficou excluída do trabalho e dos bens e serviços de nossa sociedade, observando-se o aumento significativo das pessoas em situação de rua. As instituições que atendem à população adulta em situação de rua, no centro da cidade de São Paulo foram diagnosticadas. Seus objetivos, ações desenvolvidas e a articulação entre tais instituições foram diagnosticados. A hipótese é que a realidade atual é formada por práticas isoladas, assistencialistas, centralizadas que sustentam e cronificam a situação de rua. Por meio da metodologia participativa, observou-se uma mudança gradativa desse modelo para a emancipação do sujeito, embora haja ainda a imposição do saber técnico e de seus valores, o que abafa a voz dessa população. A formação de uma rede social pautada em ações intersetoriais, na perspectiva da Promoção da Saúde, é uma possibilidade na construção e gestão de políticas públicas inovadoras.
\end{abstract}

\section{DESCRITORES}

Sem-teto.

Promoção da saúde.

Redes comunitárias.

Condições sociais.

\begin{abstract}
One of the outcomes of globalization has been a constant increase of the number of people living in the streets of metropolis such as São Paulo: those are not only homeless, but also people who live in the streets and earn their living from it. We have surveyed the institutions working with adult homeless population in the central region of Sao Paulo. Their goals and strategies were described, as well as how they associate with each other. Our main hypothesis is that our reality is still formed by isolated actions, based on mere assistance policies that help to maintain the problem of homelessness and turn it into a chronicle situation. Although, the participative methodology we chose has shown a small change from this model towards the idea of the emancipation of the subject. Even so, the idea of a technical knowledge still looms large and keeps the voice of the population in the background. The constitution of a network based on inter-sectorial actions (according to the perspective of health promotion) indicates the possibility of building innovatory public policies.
\end{abstract}

\section{KEY WORDS}

Homeless persons.

Health promotion.

Community networks.

Social condutions.

\section{RESUMEN}

Con la aceleración de la globalización, una parte de la población se ha quedado excluida del trabajo, y de los bienes y servicios de nuestra sociedad, observándose un aumento significativo de las personas que viven en las calles. Este estudio analizó las instituciones, localizadas en el centro de la ciudad de São Paulo, que atienden a la población adulta que viven en la calle. Se identificaron sus objetivos, acciones ejecutadas y la articulación entre tales instituciones. La hipótesis es que la realidad actual está formada por prácticas aisladas, asistencialistas e centralizadas que sustentan y tornan crónica la situación de vivir en las calles. Por medio de la metodología participativa, se observó que hay cambios graduales de ese modelo para o de emancipación del sujeto. Aunque todavía exista la imposición del saber técnico y de sus valores, que sofoca la voz de esa población. La formación de una red social, pautada en acciones intersectoriales y en la perspectiva de la promoción de la salud, es una posibilidad para la construcción y gestión de políticas públicas innovadoras.

\section{DESCRIPTORES}

Personas sin hogar.

Promoción de la salud.

Redes comunitarias.

Condiciones sociales. 


\section{INTRODUÇÃO}

Os países da América Latina acumulam historicamente uma desigualdade social estrutural que, nas últimas décadas, foi acentuada pelo processo de aceleração da globalização e das suas consequiências negativas: grande parte da população dos países em desenvolvimento não tem acesso ao mercado de trabalho, aos bens e serviços da sociedade, o que se reflete condições desfavoráveis de vida e de saúde ${ }^{(1)}$.

A exclusão, que segundo um autor ${ }^{(2)}$, é um processo dinâmico no qual os indivíduos transitam da integração à vulnerabilidade, ou deslizam da vulnerabilidade para a inexistência social, fenômeno cada vez mais evidente nas grandes metrópoles brasileiras.

Como exemplo, podemos citar a cidade de São Paulo que, em 2003, contava com aproximadamente 10.399 pessoas vivendo em situação de rua $^{(3)}$.

Assim, pensar na complexidade que envolve esta categoria desigualdade requer uma análise dos dados macro-estruturais e conjunturais pertinentes às três últimas décadas, que indicam transformações socioeconômicas relacionadas ao surgimento e crescimento de tal fenômeno no Brasil ${ }^{(4)}$.

\section{PERFIL DOS "DESCARTÁVEIS URBANOS"(a) - QUEM SÃO E ONDE ESTÃO?}

Em 2003, a Fundação e Instituto de Pesquisas Econômicas (FIPE) $)^{(3)}$, definiu a população em situação de rua como:

Seguimento de baixíssima renda que, por contingência temporária ou de forma permanente, pernoita nos logradouros da cidade - praças, calçadas, marquises, jardins, baixos de viaduto, em locais abandonados, terrenos baldios, mocós, cemitérios e carcaças de veículos. Ou também aqueles que pernoitam em albergues públicos ou de organizações sociais.

O Quadro 1, mostra o número estimado desta população; a maioria adultos com idade entre 26 e 55 anos. Quanto ao gênero, há predominância do sexo masculino ${ }^{(3)}$. Esse dado importante confirma o que relatam Varanda e Adorno sobre a

perda do papel de provedor que afeta principalmente o homem que busca reforçar a sua identidade masculina de outras formas, através dos papéis que lhe são atribuídos nos grupos onde estabelece relações ${ }^{(4)}$.

Sem condições de prover sustento à família, os homens permanecem na condição de moradores de rua, onde encontram uma identidade possível.

(a) O termo "DESCARTÁVEIS URBANOS" é uma alusão feita à população em situação de rua, feita por Adorno e Varanda (2004) em seu artigo: Descartáveis urbanos: discutindo a complexidade da população de rua e o desafio para políticas públicas de saúde.
No que se refere à institucionalização, identificamos uma inversão do quadro, ao verificar que, em 2000, o número de pessoas nas ruas era maior que as institucionalizadas em albergues e, em 2003, provavelmente devido ao aumento de vagas nesses equipamentos, houve aumento do número de pessoas institucionalizadas. Mesmo assim, é significativo o número de pessoas nas ruas.

Quadro 1 - Caracterização da população em situação de rua da cidade de São Paulo nos anos de 2000 e 2003 - São Paulo - 2003

\begin{tabular}{|l|l|}
\hline $\mathbf{2 0 0 0}$ & $\mathbf{2 0 0 3}$ \\
\hline 8.088 pessoas em situação de rua & 10.399 pessoas em situação de rua \\
$80,6 \%$ sexo masculino & $83,4 \%$ sexo masculino \\
$61,6 \%$ adultos (26 a 55 anos) & $65,8 \%$ adultos (26 a 55 anos) \\
$45,7 \%$ albergados & $59,5 \%$ albergados \\
$54,3 \%$ na rua & $40,5 \%$ na rua \\
\hline
\end{tabular}

Os membros dessa população geralmente são denominados pessoas de rua ou morador de rua. Dada a complexidade da situação de rua diante dos vários fatores determinantes de tal fenômeno e das práticas assistencialistas ainda presentes, o estudo, citado pelos autores ${ }^{(4)}$, distingue ficar na rua circunstancialmente, estar na rua recentemente e ser de rua permanentemente, sendo este último um fator de cronificação dessa situação.

Os programas sociais,

são programas marcados pela institucionalização de práticas que visam à retirada dessas pessoas das ruas, oferecendo, entretanto, poucas possibilidades de uma reestruturação de suas vidas ${ }^{(4)}$,

considerados dessa forma como descartáveis urbanos, e ainda, eles trazem a marca ideológica do descarte social de uma população que é tratada como excedente.

Nas ruas da cidade, é significativo o número de pessoas vitimizadas pelos problemas estruturais e em condições insalubres, sujeitas à violência ou ainda sob ação contínua de álcool e drogas ${ }^{(4)}$. Trata-se de um problema de grande complexidade, sendo necessárias parcerias, ações integradoras e intersetoriais, bem como a troca de informações entre os diferentes atores para o atenuá-lo ou solucioná-lo( ${ }^{(5)}$.

\section{REDE SOCIAL E PROMOÇÃO DA SAÚDE}

Dados históricos comprovam que o fenômeno população em situação de rua acentua-se e torna-se gradativamente crescente a partir dos anos 70, quando começaram a aparecer com mais freqüência o registro de pessoas sem ganho definido vivendo nas ruas das grandes cidades, cuja designação foi sendo substituída de mendigos por moradores de 
rua ou população de rua ${ }^{(4)}$. Hoje, é muito comum a transitoriedade casa-rua por uma grande parte destas pessoas que, por diversos motivos (estrutura familiar, trabalho, drogadição, outros), ocupam os espaços públicos ou utilizam os equipamentos sociais para se abrigar e morar periodicamente. Por este motivo, o termo mais utilizado atualmente é população em situação de rua.

$\mathrm{O}$ atendimento a essas pessoas também sofreu modificações históricas. Por não terem direito à saúde, no período que antecedeu a VIII Conferência Nacional de Saúde, as pessoas em situação de rua, então denominadas mendigos, indigentes e, menos remotamente, população de rua, eram assistidas por entidades sociais e de cunho religioso e/ou filantrópico, como as Santas Casas de Misericórdia, e pela Secretaria de Assistência Social.

Mais recentemente e partir da implementação do Sistema Único de Saúde (SUS), que preconiza que a saúde é um direito de todos e um dever do Estado ${ }^{(6)}$, o sistema tende a contemplar também esta população altamente vulnerável, no que se refere aos hábitos e condições de vida (drogadição, álcool, prostituição, sofrimento psíquico e outros).

O setor saúde entra sistematicamente em cena na cidade de São Paulo em 2004. Até então, o atendimento básico geralmente realizava-se nos albergues, casas de convivência e de cuidados. Só após a manifestação do Dia Nacional de Luta da População em Situação de Rua (26 de junho de 2003) - no qual representações dessa população, de forma organizada e expressiva, reivindicaram o direito à saúde - é que surge o projeto A Gente na Rua - que tem o objetivo de viabilizar o acesso aos serviços de saúde e garantir uma atenção integral às necessidades desta população, com enfoque importante na emancipação destes.

Utilizamos os conceitos de Promoção da Saúde e Rede Social que possibilitaram a definição do objetivo do trabalho, diante da hipótese de que se faz necessário a formação ou fortalecimento de rede de apoio e de serviços que utilize uma metodologia de emancipação do sujeito, que incentive a participação, respeite a diversidade e desenvolva o protagonismo $^{(7)}$, já que a realidade atual ainda é formada por práticas isoladas, assistencialistas e centralizadas que sustentam e cronificam a situação de rua.

Encontramos no conceito de Rede Social uma possibilidade de inovação na forma de pensar e atuar nessa problemática. Trata-se de uma estrutura na qual

seus integrantes se ligam horizontalmente a todos os demais, diretamente ou através dos que o cercam. O conjunto resultante é como uma malha de múltiplos fios, que pode se espalhar indefinidamente para todos os lados, sem que nenhum de seus nós possa ser considerado principal ou central, nem representante dos demais ${ }^{(8)}$.

A Carta de Ottawa ${ }^{(9)}$ foi um documento norteador importante, pois define Promoção da Saúde, como:
Promoção da saúde é o nome dado ao processo de capacitação da comunidade para atuar na melhoria de sua qualidade de vida e saúde, incluindo uma maior participação no controle deste processo.[...] a promoção da saúde não é responsabilidade exclusiva do setor saúde, e vai para além de um estilo de vida saudável, na direção de um bem-estar global.

No âmbito da Saúde Pública, a atuação do Estado transcende o atendimento a estas pessoas em condições precárias de vida e de saúde, extrapolando para o que se refere à

articulação de políticas públicas integradoras das populações com necessidades especiais, tendo em vista os princípios da universalização, eqüidade e integralidade preconizados pelo SUS ${ }^{(4)}$.

A participação e o controle social, aspectos também muito importantes neste processo, permitem que os atores envolvidos, através da gestão social e ações eficazes, possam transformar a cidade em um espaço de produção social da saúde, visando minimizar e/ou erradicar as iniqüidades existentes $^{(10)}$.

\section{Contudo,}

é necessário mais do que o acesso a serviços -assistenciais de qualidade, é preciso enfrentar os determinantes da saúde em toda a sua amplitude, o que requer políticas públicas saudáveis, uma efetiva articulação intersetorial do poder público e a mobilização da população(11).

Esta articulação intersetorial, segundo um estudo, citado pelos autores ${ }^{(12)}$

consiste nas articulações dos setores em redes de parcerias entre órgãos governamentais, não governamentais e a comunidade, na resolução de problemas prioritários de uma população que vive em determinado território;

acrescentam ainda que tais parcerias podem extrapolar para os níveis de governo.

A busca de soluções pertinentes e eficazes para os problemas, visando uma articulação que compreenda os diferentes saberes de uma forma não hierarquizada e cooperativa, é condição vital para a construção de uma rede social que preconize estratégias de promoção da saúde.

Salientamos que este trabalho não seria possível sem a compreensão das definições sobre a exclusão social, que também complementaram o referencial teórico, pela pertinência com o tema.

a exclusão pode ser definida como um processo múltiplo de separação de grupos e sujeitos presente e combinado nas relações econômicas, sociais, culturais e políticas, resultando disso a pobreza, discriminação, não acessibilidade ao mundo do trabalho e do consumo e a não representação social e pública(1). 
A complementaridade desses conceitos permitiu que se entendesse com maior clareza os acontecimentos presentes na história de vida do povo da rua: empobrecimento, perda de vínculos familiares, perda de emprego, perda de identidade, adoecimento, dentre outros.

\section{OBJETIVO}

Com o intuito de conhecer a metodologia de trabalho utilizada pelas instituições que atendem a população em situação de rua; contribuir para o fortalecimento das redes existentes, através da identificação de potencialidades e dificuldades, e colaborar para a construção de um modelo/sistema/proposta de atendimento integral para esta parte da população desprovida de acessos e recursos, determinouse como objetivo principal do trabalho realizar um diagnóstico das instituições públicas, privadas e as entidades sociais que têm como público-alvo as pessoas adultas em situação de rua, na região central do município de São Paulo, identificando seus princípios norteadores, através de seus objetivos, das ações executadas e da articulação com outros setores.

\section{MÉTODO}

Após o levantamento bibliográfico sobre o tema, iniciamos a delimitação do campo de investigação, baseada na pesquisa da $\operatorname{FIPE}^{(3)}$, que destaca o centro da cidade de São Paulo como a região com maior número de moradores de rua. Sendo assim, para demarcar um território específico dessa região, optou-se pela área de abrangência da Unidade Básica de Saúde Humaitá, que compreende as regiões: Sé, Bela Vista e parte da Liberdade e República. Optou-se também por trabalhar com os equipamentos que atendem a população adulta dessa região, visto que também existem equipamentos que atendem crianças, jovens e adolescentes. A relação dos 19 equipamentos de interesse para o trabalho foi disponibilizada pela Secretaria de Assistência e Desenvolvimento Social (SMADS).

Para o desenvolvimento desta pesquisa, optou-se por uma metodologia participativa, mais especificamente a pesquisa-ação ${ }^{(13)}$. A coleta de dados iniciou-se com a aplicação de um questionário semi-estrutrurado para representantes de todos os equipamentos listados na área delimitada, instrumento este que foi readequado após a aplicação do préteste. Posteriormente, foi proposta uma oficina participativa, que contou com a participação de cinco equipamentos, na qual foram desenvolvidas discussões e reflexões que permitiram a confecção de um quadro de figuras e um sociograma, os quais demonstraram o conhecimento e o relacionamento interinstitucional. Esse momento também utilizou da técnica de dramatização inspirada no Teatro do Oprimido, de Augusto Boal ${ }^{(14)}$, que complementou e enriqueceu a coleta de dados, permitindo captar ainda mais emoções e subjetivida- des. O material colhido forneceu dados que sugeriram uma análise quali-quantitativa.

\section{RESULTADOS}

Durante a oficina, percebeu-se um grande envolvimento entre as instituições, evidenciado pela participação e resultados obtidos. Estabeleceu-se entre elas uma relação mútua, inclusive entre as instituições que até o momento da oficina não se conheciam. Considerou-se que este momento propiciou uma comunicação que consolida um dos objetivos do trabalho, que é o de fortalecer esse vínculo no estabelecimento da rede e que confirma a importância da metodologia utilizada como

\section{processo pedagógico problematizador, que reconhece o indivíduo como sujeito da ação estimulando a participação crítica e valorizando os seus conhecimentos acerca da problemática desenvolvida ${ }^{(15)}$.}

De acordo com os discursos obtidos na dramatização observou-se que, por um lado, as instituições e a população de um modo geral vêem a pessoa em situação de rua como um ser desprovido de tudo, inclusive de história, vontades, valores e costumes. Com o intuito de resolver o problema alheio, costuma-se impor valores próprios, desconsiderando o direito de decisão dessa população, que deve aceitar tudo que eu acho melhor para ela. Essas afirmações corroboram a nossa hipótese de que a visão assistencialista e caritativa continua presente no imaginário social e nas ações das instituições.

Por outro lado, os dados obtidos nos questionários, relativos às missões e atividades desenvolvidas pelas instituições, apresentam termos como emancipação, direitos, geração de renda, cidadania e rede social.

Apareceram as categorias Emancipação, Promoção da Saúde e Rede Social. Em relação ao objetivo das instituições, as categorias atendimento e emancipação foram igualmente representadas.

\section{CONSIDERAÇÕES FINAIS}

Embora resultados demonstrem um avanço no discurso das instituições, o que evidencia a preocupação e interesse na substituição de uma atenção voltada para ações assistencialistas, por uma de emancipação do sujeito, com a valorização do protagonismo social, esse é um processo que, além da participação efetiva da população de rua, requer a revisão dos conceitos e a reflexão sobre as práticas, atentando para a coerência entre eles.

Como dificultadores desse processo, pôde-se constatar o desencontro de informações, o despreparo das equipes para o trabalho em conjunto, a centralização dos poderes e a 
hierarquização, além dos interesses políticos e econômicos que se encontram em jogo em todas as relações.

O setor saúde exerce uma influência positiva no processo de articulação das ações na composição dessa rede de serviços, devido a sua trajetória histórica na elaboração de uma política pública pautada nos princípios do SUS: universalidade, integralidade e equidade.

Ações intersetoriais e intersecretariais aqui representadas carecem da participação mais efetiva do setor trabalho e do setor habitação, pois, na problemática aqui apresentada, tal participação é de fundamental importância para uma transformação real nas condições de vida e saúde da população em situação de rua.

Uma visão assistencialista dos indigentes vem sendo substituída gradativamente por um discurso de inclusão social, empoderamento e cidadania. Apesar disso, o saber técnico e a imposição de valores ainda prevalecem, o que su- põe pouca articulação com os representantes das pessoas em situação de rua e pouca escuta de suas necessidades. A representatividade da pessoa em situação de rua nesta rede, além de contemplar sua composição, aproxima todos os envolvidos da realidade, e favorece a construção e o planejamento de ações mais eficazes.

O que se realiza ainda hoje são políticas paliativas e muitas vezes cronificantes, que ainda trazem no seu bojo resquícios higienistas e sanitaristas, na ótica da remoção das populações em circulação pelas cidades $^{(16)}$.

É necessária então, a continuidade desse processo de formação e fortalecimento da rede, pois mudanças de paradigma acontecem lenta e gradativamente. O setor saúde tem um papel importante nessa tessitura, na perspectiva da Promoção da Saúde. Portanto, como afirma o estudo ${ }^{(17)}$, faz-se necessária a substituição de um pensamento disjuntivo e redutor por um do complexo, considerando o sentido originário do termo complexus: o que é tecido junto.

\section{REFERÊNCIAS}

1. Minayo MCS. Condiciones de vida, desigualdad y salud a partir del caso brasileño. In: Briceño R, Minayo MCS, Coimbra Juniorr CEA, organizadores. Salud y equidad: una mirada desde las ciencias sociales. Rio de Janeiro: FIOCRUZ; 2001. p. 55-71.

2. Castell R. As metamorfoses da questão social: uma crônica do salário. Petrópolis: Vozes; 1998.

3. Fundação Instituto de Pesquisas Econômicas (FIPE). Censo dos Moradores de Rua da Cidade de São Paulo. São Paulo: Secretaria Municipal de Assistência Social; 2003.

4.Varanda W, Adorno RCF. Descartáveis urbanos: discutindo a complexidade da população de rua e o desafio para políticas públicas de saúde. Saúde Soc. 2004;13(1):56-67.

5. Mendes R, Bógus CM, Akerman M. Agendas urbanas intersetoriais em quatro cidades de São Paulo. Saúde Soc. 2004;13(1):47-55.

6. Brasil.Constituição da República Federativa do Brasil, 1988. Brasília: Senado Federal; 1990.

7. Schlithler CRB. Redes de desenvolvimento comunitário: iniciativas para a transformação social. São Paulo: Global/Instituto para o Desenvolvimento de Investimento Social; 2004.

8. Serviço Nacional do Comércio (SENAC). Programa Formatos Brasil [homepage na Internet]. São Paulo; 2007. [citado 2007 jul. 25]. Disponível em: http://www1.sp.senac.br/terceirosetor/ formatos/oque.asp
9. Brasil. Ministério da Saúde. Secretaria de Políticas de Saúde. Projeto Promoção da Saúde. As Cartas de Promoção da Saúde. Brasília; 2002.

10. Westphal MF, Mendes R. Cidade saudável: uma experiência de interdisciplinaridade e intersetorialidade. Rev Adm Pública. 2000;34(6):47-61.

11. Buss PM. Promoção da saúde e qualidade de vida. Ciênc Saúde Coletiva. 2000;5(1):163-77.

12. Westphal MF, Mendes R. Cidade saudável: uma experiência de interdisciplinaridade e intersetorialidade. Rev Adm Pública. 2000;34(6):47- 61.

13. Thiollent M. Metodologia da pesquisa-ação. $9^{\mathrm{a}}$ ed. São Paulo: Cortez; 2000.

14. Boal A. Teatro do Oprimido e outras poéticas políticas. Rio de Janeiro: Civilização Brasileira; 1991.

15. Chiesa AM, Westphal MF. A sistematização de Oficinas Educativas Problematizadoras no contexto dos Serviços Públicos de Saúde. Saúde Debate. 1995;(46):19-22.

16. Foucault M. Microfísica do poder. Rio de Janeiro: Graal; 1979.

17. Morin E. A cabeça bem feita: pensar a reforma - reformar o pensamento. $9^{a}$ ed. Rio de Janeiro: Bertrand Brasil; 2004. 